\title{
Os conflitos pela terra no Amapá: uma análise sobre a violência institucionalizada no campo
}

\author{
Roni Mayer Lomba \\ Programa de Pós-Graduação em Desenvolvimento Regional da Universidade Federal do Amapá (Unifap) \\ Júnior Gomes da Silva \\ Geógrafo pela Universidade Federal do Amapá (Unifap)
}

Recebido: 04/05/2014 Versão revisada (entregue): 08/12/2014 Aprovado: 10/03/2015

\begin{abstract}
Resumo
O texto aborda a dinâmica dos conflitos fundiários no Estado do Amapá. O trabalho resgata a gênese desse processo, apresentado pela política e pela mídia como uma relação pacífica no campo. Na realidade, contudo, o Amapá constitui um dos estados da Federação com significativas incidências de disputas por terra. Para a realização da pesquisa foram coletados dados, especialmente, da Comissão Pastoral da Terra, por meio dos seus registros anuais (Conflitos no Campo); mas também foram realizados levantamentos sobre a dinâmica do campesinato e sua recriação no Amapá. Ficou constatado que a violência no campo está instaurada pela disputa entre camponeses (posseiros, ribeirinhos, extrativistas e quilombolas) e grandes empresas (mineradoras, silvicultoras e agropecuárias), envolvendo inclusive o próprio Estado, responsável pela criação de grandes áreas de preservação sem a regularização necessária.
\end{abstract}

Palavras-chave | Amapá; campesinato; conflitos por terras; violência.

Código JEL | Q24; Q58; R14.

\section{CONFLICTS IN AMAPÁ: AN ANALYSIS ON THE INSTITUTIONALIZED VIOLENCE IN THE COUNTRYSIDE}

\begin{abstract}
The text addresses the dynamics of land conflicts in the state of Amapá. The work recalls the genesis of this process, presented by politics and the media as a peaceful relationship in the countryside. In reality, however, Amapá is one of the states of the Federation with significant implications on land disputes. For the research, data were collected, especially in Pastoral da Terra Commission, through its annual records (Conflicts in the Countryside); also, surveys were conducted on the dynamics of the peasantry and its recreation in Amapá. It was verified that violence in the countryside is established by the dispute among farmers (squatters, riparian people, extractivist and Quilombo people's ancestors) and large companies (mining, sylviculture
\end{abstract}


companies and agricultural), including the State itself, which is responsible for the creation of large areas of preservation without the required regularization.

Keywords | Amapá; conflicts over land; peasantry; violence.

JEL-Code | Q24; Q58; R14.

\section{LOS CONFLICTOS POR LA TIERRA EN AMAPÁ: UN ANÁLISIS DE LA VIOLENCIA INSTITUCIONALIZADA EN EL CAMPO}

\section{Resumen}

El texto aborda la dinámica de los conflictos por la tierra en el estado de Amapá. El artículo recupera la génesis de este proceso, presentado por la política y los medios de comunicación como una relación pacífica en el campo. En realidad, el Amapá es uno de los estados brasileños con relevantes incidencias en conflictos de tierras. En la investigación se recopilaron datos, especialmente, de la Comisión Pastoral de la Tierra, a través de sus registros anuales (Conflictos en el Campo); pero también se llevaron a cabo encuestas sobre la dinámica de los campesinos y su reproducción en Amapá. Se demostró que la violencia en el campo es establecida por la disputa entre los campesinos (posseiros, ribereños, extractivistas y quilombolas) y las grandes empresas (mineras, silvicultoras y agrícolas), incluyendo la participación del propio Estado, responsable por la creación de grandes áreas de preservación ambiental sin la necesaria regularización.

Palabras-clave | Amapá; campesinos; conflictos por la tierra; violencia.

Código JEL | Q24; Q58; R14.

\section{Introdução}

O presente trabalho analisa a dinâmica dos conflitos pela terra no Estado do Amapá, por meio dos dados coletados junto à Comissão Pastoral da Terra - CPT no período entre 2002 a 2011 e por entrevistas junto aos representantes da comissão.

O trabalho descaracteriza a ideologia ou o mito de que no Amapá não existem conflitos fundiários. É notório que a mídia e parte da sociedade local só reconhecem a existência de conflitos no campo quando há agressão física ou a morte de envolvidos. No entanto, é fato que os conflitos no Amapá estão mais vinculados à pressão moral, pelo constrangimento à cidadania dos sujeitos, com o uso de outras formas de violência que buscam coagir o camponês e o pressionam a vender a preços irrisórios seu lugar de moradia e a terra de lavra ou as áreas de pesca. Registram-se também casos de destruição de roças e de casas de camponeses por enviados de empresas capitalistas ou por representantes do poder judiciário, para fins de reintegração de posse, garantindo o interesse de supostos "proprietários". 
O conflito pela terra no Amapá é realizado basicamente por dois agentes: por empresas capitalistas (fazendeiros, madeireiros, mineradoras e garimpos) e pelo Estado, com a criação de áreas de preservação de proteção integral. Do outro lado, os posseiros compõem a parte mais sensível desse processo, pois, por não possuírem terras reconhecidas pelo Estado, ficam à margem do processo e sujeitos a pressões diversas. Os conflitos, porém, não estão restritos às terras de posseiros, mas se estendem aos quilombolas, aos indígenas e aos assentados da reforma agrária, sendo o Instituto Nacional de Colonização e Reforma Agrária - Incra um dos maiores responsáveis pelos conflitos no Amapá, decorrentes da forma equivocada de realizar assentamentos.

O trabalho apresenta-se, portanto, como ensaio para uma discussão sobre os conflitos pela terra no Amapá, as políticas territoriais adotadas e os dilemas que envolvem o campo amapaense.

\section{Histórico fundiário e características territoriais do Amapá}

A estrutura fundiária amapaense ganhou seu sentido mais moderno com a criação do Território Federal do Amapá em 1943. Segundo Jorge (2003), entre 1901 a 1943 - período que vai da integração definitiva do Amapá ao restante do Brasil (após a resolução do litígio do Contestado) até a criação do Território Federal -, a ocupação dos territórios locais se caracterizou pelo povoamento com pequenas ilhas quase incomunicáveis, sem força de expansão e com enormes vazios, obedecendo ao padrão de ocupação amazônico dependente das condições hidrográficas. Até a criação do território, os municípios de Macapá, Amapá e Mazagão tinham uma população muito reduzida e atividade econômica irrelevante, sendo que basicamente suas atividades se limitavam à exploração de ouro e à criação de gado, que abastecia os mineradores, além da coleta de borracha ou castanha na área mais próxima ao rio Amazonas, coleta que sustentava uma reduzida população (JORGE, 2003).

Esse cenário se transformou com a criação do Território Federal do Amapá. Para Raiol (1992), a política de segurança nacional que mascarou a criação do território não vislumbrava somente o povoamento das terras fronteiriças amapaenses, mas representava também o interesse do grande capital estrangeiro em explorar os seus recursos naturais, principalmente as estratégicas jazidas manganíferas do Amapá em plena Guerra Fria, dando início à apropriação contemporânea do capital sobre os territórios locais.

Conforme Raiol (1992, p. 18),

É a partir da era ICOMI/Bethlem Steel que a história social da terra no Amapá passa a sofrer uma mudança que vai repercutir profundamente 
no modo de vida do camponês. É uma história de sofrimento, de lenta expropriação da terra camponesa na medida em que a política governamental promove, mais adiante, mudanças no processo de ocupação da Amazônia a se destacar, particularmente, em março de 1967, com a chegada do bilionário americano Daniel Keith Ludwing.

A mudança a que o autor se refere, na verdade, foi uma política de favorecimento à formação de grandes latifúndios no Amapá, haja visto que o Decreto-Lei $n^{\circ}$ 1.164/71 - o qual tratava da indispensabilidade na Amazônia Legal das terras devolutas situadas na faixa de $100 \mathrm{~km}$ de largura em cada lado das rodovias federais, combinado a Lei $\mathrm{n}^{\circ} 2.597 / 55$, que versava sobre a faixa de fronteira com os países vizinhos - incorporou 90\% das terras do Amapá aos bens da União, que depois eram barganhadas e distribuídas a critério do governo federal. Nesse cenário, o avanço do capital sobre as terras no Amapá não pode ser pensado dissociado de uma estratégica política de concentração de terras implantadas pelo próprio Estado (LIMA, 2008; RAIOL, 1992).

Para isso, foram pensados e criados arranjos fundiários como o Projeto Fundiário do Amapá, em 1973. De acordo com Lima (2008), durante a implantação do Projeto Fundiário do Amapá, o Incra promoveu ações que de um lado agilizaram a legalização de muitas parcelas de terras amapaenses, mas que de outro ensejaram a legitimação de grandes propriedades, sendo que em muitas delas o processo ocorreu de forma irregular.

Como exemplo disso, temos o processo de alienação de terras públicas no Amapá pela Concorrência Pública no ${ }^{\circ}$ 1/78/Incra/DF que trazia um detalhe relevante: cada empresa poderia concorrer a uma única parcela de terra. Porém, segundo Lima (2008), o grupo Caemi forjou a participação das próprias empresas como, por exemplo, a Icomi e a Amcel, entre outras, sendo firmado, junto ao Incra, um contrato de compra e venda das terras com as empresas do mesmo grupo. Em 1984, as parcelas de terras vendidas ao grupo e já dotadas de títulos definitivos passaram a ser controladas unicamente pela Amcel, que passou a ser proprietária de um imóvel rural de 155.577 ha, sendo que ao serem demarcadas aumentaram em $11 \%$, chegando a 171.987 ha.

O Projeto Fundiário do Amapá pode ser dividido em outros dois projetos menores: o Distrito Agropecuário do Amapá, que abrangia uma área de 600.000 ha, em sua maioria de florestas tropicais, e visava atividades de horticultura, agricultura, pecuária etc., com distribuição de parcelas de terras que variavam de 100 a 15.000 ha, tendo como objetivo elevar o potencial agrícola e de abastecimento do Amapá por meio da estratégia de ocupação dos territórios pelo viés da concentração de áreas em determinadas companhias. Na realidade, este projeto se baseou na conversão da floresta em pastagem para o gado (LIMA, 2008). 
O outro projeto seria o Distrito Florestal do Amapá, que se situava na porção central do Estado e foi planejado para a plantação e cultivo de pinus pela Amcel, criado em 1976, o que imobilizou cerca de 1,5 milhões de hectares de terras públicas para a implantação do projeto da empresa. Desse modo, não há mais dúvidas a respeito de que forma ocorreu a apropriação das terras amapaenses pelo grande capital (LIMA, 2008).

Conforme Torrinha (2006), a concentração de terras que esses programas estatais criaram no Território Federal é um dos principais elementos para se explicar os atuais conflitos pela terra no Amapá, pois à medida que crescia a concentração de terras, se avolumava também o número de conflitos. Na década de 1980, o Amapá representava um paraíso para os latifundiários, com propriedades que chegavam a se configurar entre os 20 maiores latifúndios do país, não apenas o caso da Jari e da Amcel, mas também da empresa fantasma Agroindustrial do Amapá S. A, que possuía mais de 460 mil ha do município do Mazagão e do latifúndio de João Francisco Martins Barata, em Calçoene, que chegou a ser o sexto maior do Brasil.

Nesse sentido, o Estado, objetivando destinar áreas a empresas que desejassem implantar grandes projetos agropecuários e florestais no Território Federal, acabou, na verdade, consolidando e legalizando grandes imóveis rurais amapaenses, como é o caso da própria Amcel, que melhor representa hoje no Amapá a configuração da terra pertencente ao capital, considerando que grandes áreas de terras locais passaram a se destinar à geração de renda fundiária por meio da exploração do trabalho, representando a lógica capitalista do uso da terra, que se contradiz com a terra do trabalho na qual o ocupante não possui o título da terra e, sendo assim, apenas o trabalho é invocado como garantia de direito (JORGE, 2003; LIMA, 2008; MARTINS, 1981).

Essa aliança entre o grande capital e o Estado no Amapá não só assenhoreou enormes parcelas de terras a algumas empresas, mas também renegou a agricultura camponesa ao segundo plano. Segundo Jorge (2003), essa política fundiária concentradora da União, iniciada nos anos de 1970, refletiu de forma contundente nos anos de 1980, uma vez que o Índice de Gini (isto é, o índice que calcula a desigualdade social) do Amapá, nessa década, era de 0.905, enquanto o do Brasil era de 0.854 , ou seja, se no país a propriedade da terra era concentrada, no Amapá ela o era ainda mais.

Para Raiol (1992), a expropriação do camponês local se deu nesse cenário de consolidação de grandes latifúndios, sendo que o mesmo era expropriado e, em seguida, era explorado, pois, para o autor, a expropriação do camponês amapaense se deu de forma muito singular: ele era separado da sua terra com a fantasia de poder alcançar a independência econômica, ao vislumbrar os altos salários proporcionados pelas grandes empresas agrominerais instaladas no então Território Federal. 
Assim, é possível afirmar que foi com a criação do Território Federal do Amapá que se consolida o açambarcamento das terras e das riquezas naturais amapaenses e, consequentemente, a expropriação e desarticulação do campesinato local, que se reflete até os dias atuais na dinâmica dos conflitos pela terra no Estado (RAIOL, 1992).

Numa perspectiva atual, pode-se afirmar que a estrutura fundiária amapaense é de complexa análise, haja vista que até hoje não foi definida uma política de destinação das terras públicas do Estado. Segundo Jorge (2003), para se obter o direito de regularizar a terra no Amapá, ainda é preciso tomar posse dela por conta e risco, edificar benfeitorias e fazer plantações, ou seja, estabelecer a posse por simples ocupação, favorecendo a ocorrência de conflitos.

Conforme Lima (2008), na segunda metade da década de 1990, um novo modelo para a gestão das terras amapaenses começou a ser introduzido, sendo dada a ênfase à proteção das florestas locais por meio de mecanismos de controle dos recursos naturais. Nesse momento, o uso da terra no Estado passa a englobar uma política governamental de sustentabilidade, traçando-se áreas prioritárias para atividades como o extrativismo.

Em resposta, observa-se uma tendência de desconcentração da propriedade da terra no Amapá. Nos anos 2000, o Índice de Gini nacional era de 0.802, enquanto o do Amapá era de 0.613, mas a participação dos imóveis menores que 100 ha continuou bastante reduzida. Em 2007, o estado apresentava um cenário fundiário marcado pela forte concentração da propriedade da terra, pois as pequenas propriedades representavam 90\% dos imóveis rurais, porém, ocupavam apenas $15,5 \%$ das terras locais, ao passo que as grandes propriedades eram apenas 2,6\% dos imóveis rurais, mas ocupavam 75,5\% das terras amapaenses (CPT, 2012; JORGE, 2003).

Outra questão importante para o atual entendimento do cenário fundiário amapaense é o fato de que a União ainda influencia bastante nos rumos da distribuição e na tomada de decisões sobre as terras no Amapá, pois controla ainda um elevado quantitativo de terras, sendo que órgãos federais como Incra, Ibama e Funai detêm cerca de $80 \%$ das terras públicas.

Sobre esse tema, foi criado em 2007 o Decreto $n^{\circ}$ 6.291, de 07/12/2007, que transferia gratuitamente ao Estado do Amapá as terras públicas federais situadas em seu território e que estivessem arrecadadas e matriculadas em nome da União. Entretanto, o órgão responsável pelo georreferenciamento e ordenamento fundiário no Estado, o Instituto de Ambiente e Ordenamento Territorial no Estado do Amapá - IMAP, vem encontrando dificuldades no que se refere aos estudos e ao firmamento de convênio com o Incra para levantar o real patrimônio fundiário amapaense. A criação de unidades de conservação e de reservas indígenas é outra temática emblemática quando se fala de política fundiária no Amapá. 
Segundo Lima (2008), as unidades de conservação somam 6.498,945 ha, os territórios indígenas somam 1.149,840 ha, sendo que as unidades de conservação circundam os territórios indígenas legitimados, formando um mosaico da preservação que possui 7.648,785 ha, 54\% das terras amapaenses. De acordo com autor, se for somado a este quantitativo 561.428 ha dos territórios de colonização do Incra, mais os 710.977 ha dos monocultivos das empresas Jari e Amcel, temos $8.921,190$ ha, isto é, 62\% dos $14.345,370$ ha existentes no território amapaense estão indisponíveis para qualquer outro tipo de atividade territorial.

Justaposto a isso, há atuações territoriais de posseiros, grileiros, garimpeiros, fazendeiros, quilombolas, ribeirinhos, assentados, dentre outros que criam no espaço amapaense contradições e antagonismos que se revelam principalmente na forma de conflitos pela da terra. No Gráfico 1 é mostrada a distribuição das terras públicas do Amapá.

\section{Gráfico 1 - Distribuição das terras do Amapá}

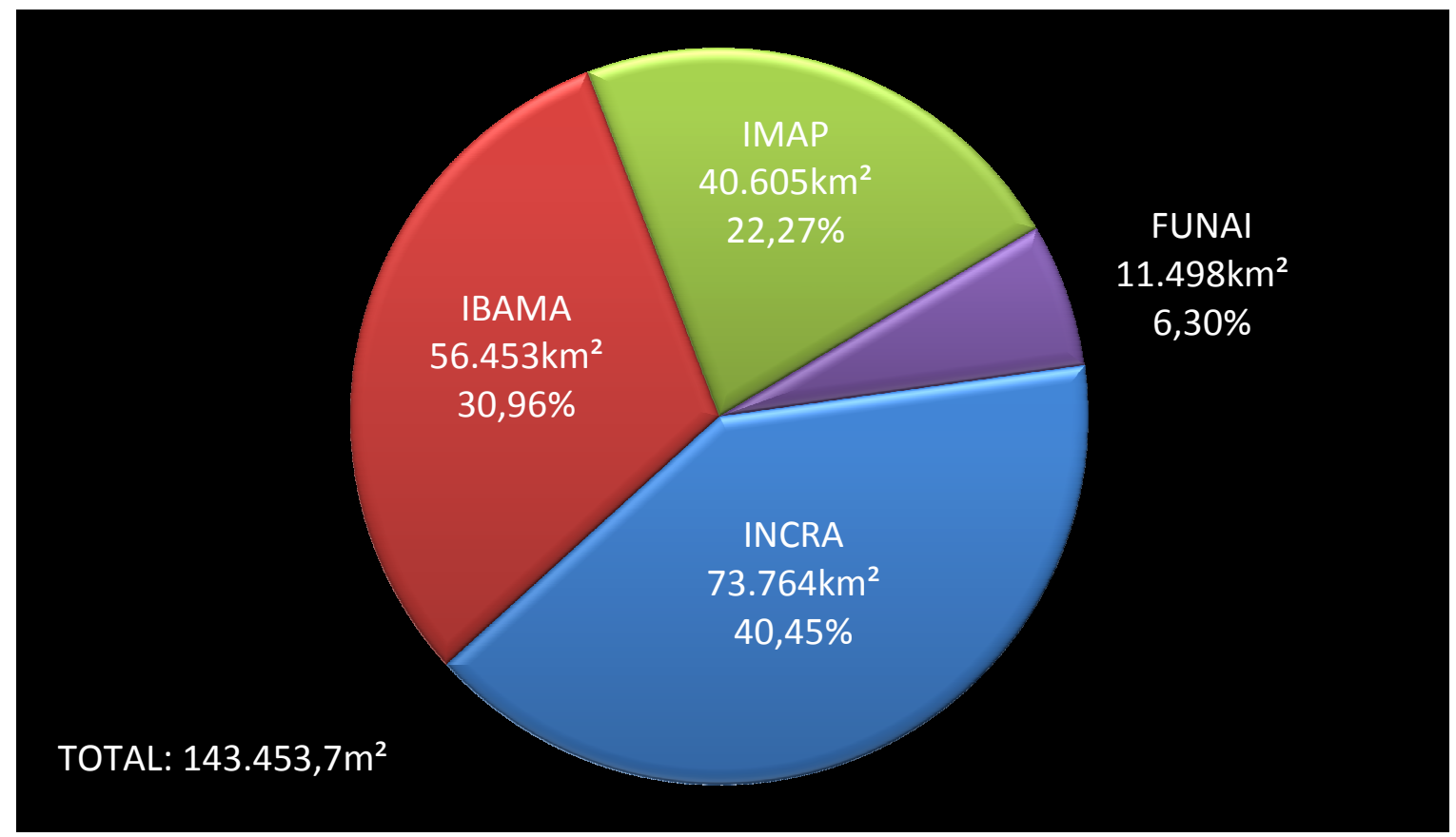

Fonte: Lima (2008), organização: Júnior Silva (2013).

Como pode ser constatado pelo Gráfico 1, a União ainda controla um elevado quantitativo de terras no Amapá, uma vez que órgãos federais como Incra, Ibama e Funai mantêm aproximadamente $80 \%$ das terras públicas amapaenses. Dessa forma, o Amapá apresenta um cenário de sobreposição de territórios por órgãos federais como o Ibama, Incra, Funai, e também latifúndios de empresas como a Amcel e Jari Celulose. 
Assim, pode-se inferir que os conflitos pela terra são frutos de ações políticas pretéritas e atuais que reconfiguram constantemente o espaço amapaense. Essas ações criam e recriam limites territoriais que, por sua vez, fazem surgir novas dinâmicas sociais em relação à propriedade da terra, resultando no cenário favorável a ocorrência de conflitos pela terra.

Todavia, mesmo diante desse cenário, poucos meios de comunicação a divulgam, ajudando a criar o mito de que no campo amapaense não existe violência. Frente a isso, apresentamos os registros de conflitos pela terra da CPT no Estado, no transcurso de 2002 a 2011, o que ajuda a entender que, além de violência no campo, há também ações de resistência dos camponeses amapaenses às ações associadas tanto do capital quanto do Estado, embora esses camponeses ainda sejam pouco organizados politicamente.

\section{Os conflitos pela terra no Amapá entre 2002 e 2011}

Inicialmente, cabe ser dito que os conflitos e a violência pela terra no Amapá não são nenhuma novidade para quem conhece a realidade do campo amapaense. Porém, é com a penetração do capitalismo - promovida pelos incentivos fiscais e arranjos fundiários estatais que concentraram a propriedade da terra em empresas de exploração agrominerais - que os conflitos pela terra irromperam no campo amapaense.

Nos anos de 1980, por exemplo, com a instalação definitiva do projeto Amcel no cerrado amapaense, as notícias da expulsão de famílias de posseiros que viviam ao longo das margens da BR-156 se tornaram comuns. Na década de 1970, a Jari Celulose entrou em conflito com moradores que estavam se estabelecendo no que seria doravante a favela do Beiradão, então município de Mazagão (RAIOL, 1992).

Os conflitos pela terra no Amapá ganharam visibilidade nacional e internacional com a bárbara chacina dos Magave, em 1993, no município de Amapá, onde foram assassinados e esquartejados cinco membros da família. A chacina ocorreu pela resistência da família às ameaças e à pressão para vender sua propriedade à empresa Santa Clara e ao fazendeiro Aderbal Távora. Outro assassinato foi o da líder do MST no município de Laranjal do Jari, Maria Nazaré Souza Mineiro, em 1998, que teve sua morte tramada por especuladores de terras do município, visto que sua atividade de remanejamento de moradores das palafitas para assentamentos em terras periurbanas apoiada por órgãos governamentais estava incomodando os interesses destes (TORRINHA, 2006).

Esses exemplos de conflitos servem para comprovar duas coisas. A primeira, que os conflitos pela terra no estado surgiram de um quadro de tensão social específico de uma área fronteiriça a que o capital chegou tardiamente, mas conseguiu dominar pontos estratégicos para a exploração da terra, sendo que o 
mito de que o Amapá está imune a grandes registros conflituosos e a suposta tênue resistência camponesa servem como pseudoexplicação para que se pense que o Amapá não possui conflitos por terra, o que resulta na negação do antagonismo existente entre diferentes atores sociais que encontram nas terras amapaenses o seu meio de sustentação de vida ou de exercício do poder econômico (RAIOL, 1993; TORRINHA 2006).

A segunda é justamente o fato de que, embora o Amapá apresente na sua história e no seu presente casos volumosos de conflitos pela terra, os mesmos não são considerados no cenário político, sendo praticamente um assunto proibido, inaceitável à realidade de um estado que historicamente é visto como sendo um vazio demográfico, constituído de terras devolutas (RAIOL, 1992).

Entretanto, a violência no campo amapaense é preocupante, pois sua população rural é uma das menores do Brasil, o que hipoteticamente deveria rebaixar os números de conflitos. Os números de 2002 a 2011 da CPT apontam que, em dez anos, mais de 11 mil famílias foram expulsas ou despejadas de suas terras, sendo que o Amapá nesse período chegou a figurar entre os estados com maior índice de conflitos pela terra em todo o país (CPT, 2012). Isso, indubitavelmente, merece ser analisado.

\section{A geografia dos conflitos pela terra no Amapá entre 2002 a 2011}

Para se entender a dinâmica dos conflitos no Amapá é necessário compreender que os conflitos pela terra no estado podem ser o resultado da ação de dois grandes segmentos. O primeiro segmento seria o institucional, em que os conflitos pela terra são vistos como produzidos pela ação direta ou indireta das instituições políticas do Estado. A negligência ou omissão de órgãos responsáveis pela execução e desenvolvimento de políticas públicas também pode ser compreendida dentro desse segmento (MANIGLIA, 2009). O segundo segmento seria o estrutural, em que os conflitos pela terra estão ligados às relações dominantes de produção capitalista, destacando-se aí atores sociais particulares como madeireiros, grileiros, fazendeiros, grandes empresas etc. Nesse segmento, a violência dos atores sociais dominantes recai geralmente sobre os camponeses (MANIGLIA, 2009).

Com isso, pode-se inferir que no Amapá os conflitos pela terra resultam da ação conjunta e indissociável desses dois segmentos. Para Raiol (1992), isso ocorre por existir uma política de manutenção de um estado de "pacificidade camponesa", que se construiu pela aliança estratégica do Estado com o capital e que visa, desde a criação do Território Federal, formar uma sociedade camponesa alienada, subserviente e marginalizada politicamente. 
Essa pacificidade não impede completamente que esses conflitos pela terra provoquem resistências no campo amapaense, porém, elas não se configuram somente na disputa e uso da propriedade da terra, mas também pela defesa e conquista de direitos e territórios em diferentes contextos sociais, sendo que sua matriz está na ausência ou má gestão de políticas públicas.

De forma geral, a resistência do camponês encontrada no Amapá não é visível em ações de ocupação ou invasão de terras, pois isso requer uma forte organização camponesa que ainda não se construiu no estado, mas deve ser compreendida como o confronto com as condições impostas pelo capital e pelo Estado que buscam o desterritorializar e o proletarizar, fazendo com que o mesmo se recrie. Assim, a violência ultrapassa a agressão física, ela é também moral, pois envolve igualmente o constrangimento e a supressão da cidadania dos camponeses que têm suas casas e roças destruídas por seguranças de empresas capitalistas ou são despejados por polícias que cumprem ordem de reintegração judicial (CPT, 2012; MARTINS, 1981).

Os registros da CPT, entre 2002 a 2011, subsidiam melhor essa análise dos conflitos e sua dinâmica no campo amapaense. Desse modo, pode-se dizer que nos dez anos analisados, o Amapá figurou entre os estados com maiores índices de violência rural no Brasil, pois apresentou 386 registros de conflitos pela terra. No Gráfico 2 é mostrada a distribuição anual dessas contendas.

\section{Gráfico 2 - Conflitos pela terra no Amapá entre 2002 a 2011}

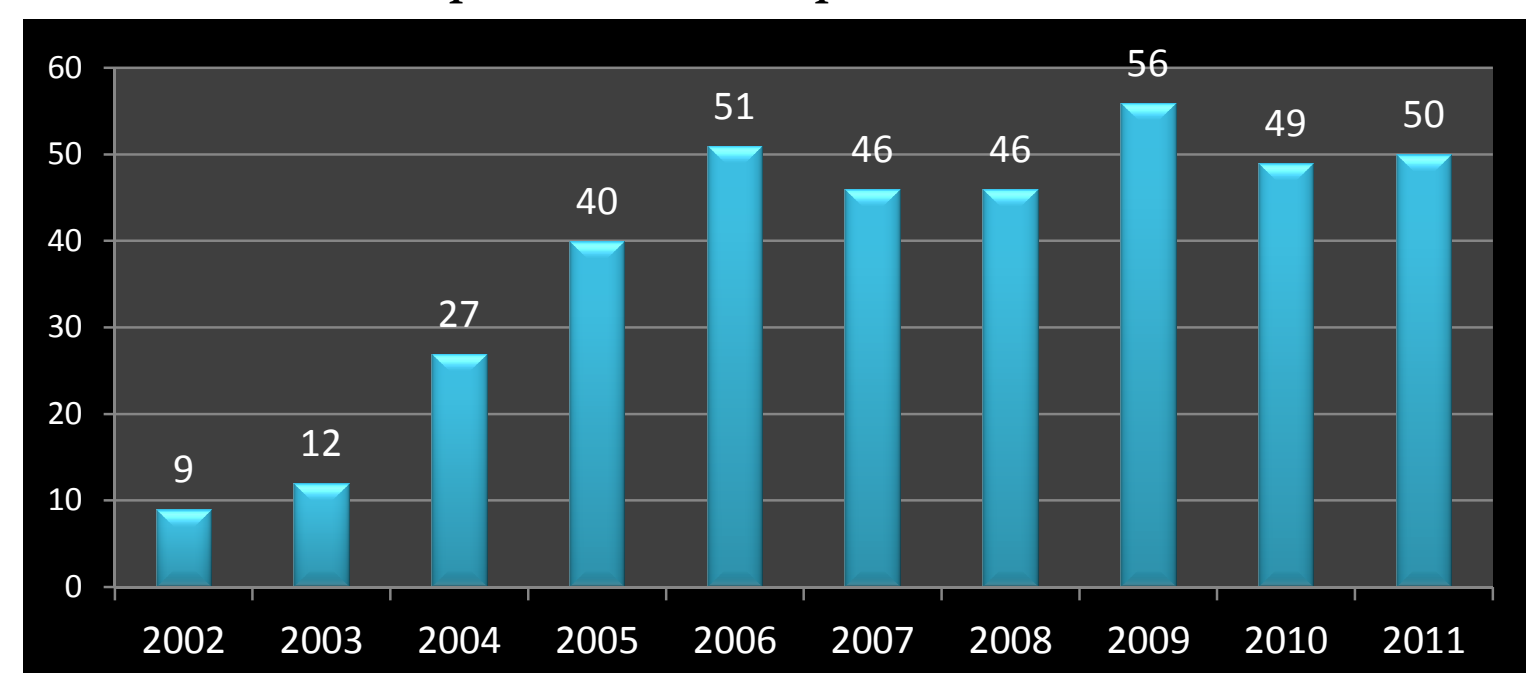

Fonte: CPT, organização: Júnior Silva (2013). 
Para melhor análise dos registros, dividiremos o período em dois quinquênios: entre 2002 a 2006 e entre 2007 a $2011^{1}$. O primeiro quinquênio apresenta um crescimento ininterrupto dos registros de casos de conflitos, saindo de nove casos em 2002, para 51, em 2006. No ano de 2005, seu índice de conflitividade, que é a proporção do número de conflitos de cada estado em relação à sua participação na população rural brasileira, foi de 14.2, isto é, naquele ano os conflitos pela terra no Amapá foram 14 vezes maiores que a sua participação na composição da população rural nacional, o que é classificado como excepcionalmente alto (GONÇALVES, 2004).

O ano de 2006 também foi bastante conflituoso, não só porque apresentou o maior número de conflitos (51 registros), mas também por ter se elevado consideravelmente a quantidade de famílias envolvidas (1.628). Esse número representa a primeira vez em que os conflitos pela terra no Amapá transcenderam a barreira de mais de mil famílias. A área disputada também nunca havia sido tão grande, tendo chegado a 243.646 ha (CPT, 2007).

Nesse período, o Amapá se destacou como sendo um dos estados com os mais altos registros de famílias camponesas expulsas de suas posses (236), assim como apresentou registros de famílias despejadas classificadas como de caráter muito alto: cerca de 2.0. O cálculo desses índices é feito pela proporção do número de pessoas envolvidas nos conflitos em relação à sua população rural. Isso significa que, nesse período, de cada quatro famílias envolvidas em conflitos pela terra no estado, pelo menos duas foram expulsas por atores particulares ou foram despejadas com o aval do poder público. Isso outorgou ao Amapá, no ano de 2005, a condição de décimo estado mais violento do país, ao lado do estado de Pernambuco (GONÇALVES, 2004).

Quanto ao quinquênio 2007 a 2011, observa-se que em 2007 apresentou-se a redução de $10 \%$ em relação ao ano de 2006 no número de casos de conflitos, um dado que se manteve inalterado em 2008 - apesar de 2007 ter apresentado a maior área disputada em dez anos (263.171 ha), e 2008, a segunda (262.371 ha). Não obstante as ocorrências diminuírem, a área em disputa aumentou, o que pode ser explicado pela implantação ou reativação de atividades agroexploradoras como os projetos de mineração da MPBA, MMX, Mineração Santa Maria, bem como a implantação de projetos de cultivo de soja e outros grãos às margens da BR-156 que intrinsecamente necessitam de uma área volumosa para se implantarem.

\footnotetext{
${ }^{1}$ A CPT nacional publica os dados sobre os conflitos no ano subsequente ao registro, isto é, os conflitos do ano de 2011 foram lançados em 2012, incluindo aí o registro de alguns conflitos ocorridos nesse ano até o fechamento da edição. Vale ser ressaltado que a CPT privilegia para o registro dos conflitos a pesquisa primária, que consiste no conhecimento do conflito "in loco", mas também utiliza a pesquisa secundária baseada em notícias de jornais, revistas etc., que, no entanto, são apuradas pelos seus agentes para serem publicados ou não.
} 
No entanto, a redução nos registros de conflitos pela terra cessa em 2009, pois esse ano apresenta o maior número absoluto de conflitos (56 registros); já 2010 (49 registros) e 2011 (50 registros), embora apresentem uma redução em relação a 2009, são, de forma geral, anos bastante conflituosos se comparados aos anos do quinquênio 2002 a 2006. A CPT (2011) apontava em 2010 que o Amapá era ainda um dos dez estados mais violentos do país. Para referência, existiam no Amapá três pessoas envolvidas em conflitos pela terra que estavam ameaçadas de morte.

O ano de 2011 não foi diferente. Em nenhum momento anterior tantas famílias se envolveram na luta pela terra no Amapá (2.185); alguns casos de conflitos chegaram a ser noticiados nos jornais, como o que envolveu um conhecido madeireiro do município de Porto Grande e famílias de posseiros que viviam há anos em uma área próxima ao km 117 da Estrada de Ferro do Amapá. O desfecho desse conflito é incerto, pois as famílias continuam na área por força da liminar impetrada pela CPT/Amapá, baseada em fundadas suspeitas de que a área em disputa foi grilada pelo madeireiro. Nesse ano, também foi registrado um caso de ameaça de morte no município de Mazagão. No Gráfico 3 é demonstrada, em percentuais, a dinâmica dos conflitos.

\section{Gráfico 3 - Evolução dos casos de conflitos por terra no Amapá 2002 a 2011}

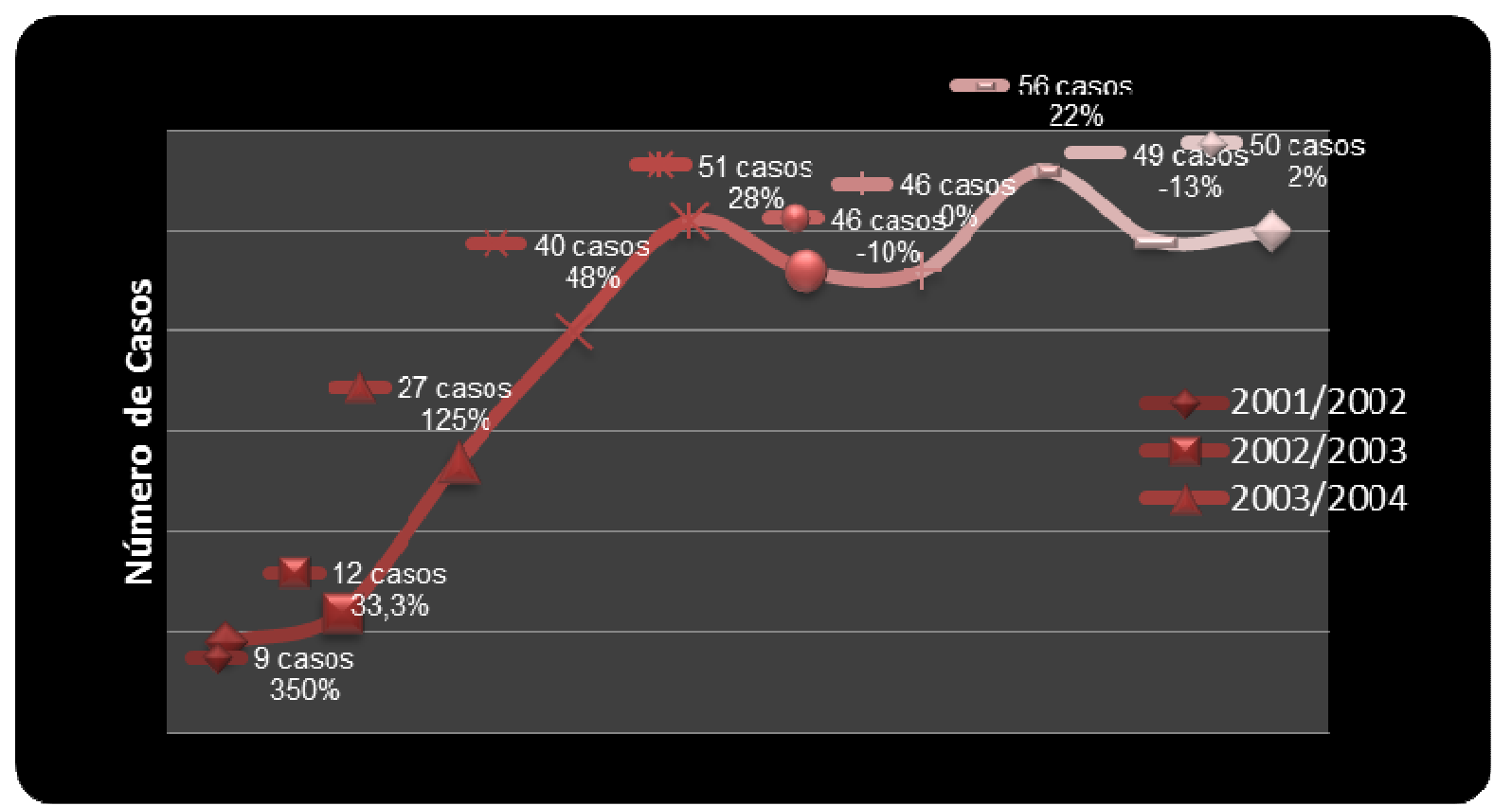

Fonte: CPT (2011), organização: Junior Gomes da Silva.

A evolução dos registros de conflitos pela terra no Amapá foi tomada comparando-se pelo ano antecessor com o seu sucessor. Assim, percebe-se que há biênios em que o crescimento foi bastante elevado, como nos anos de 2001 (2 registros) para 2002 (9 registros), perfazendo um aumento de 350\%. Outro ano 
que apresentou um crescimento extremamente elevado foi o de 2003, pois no ano de 2002 registraram-se 12 casos, enquanto em 2003 aumentaram para 27, um aumento percentual de $125 \%$.

Desse modo, embora apresente anos com redução no número de registros, como ocorreu nos anos de 2007, 2008 e 2010, os conflitos pela terra no Amapá apresentaram, em geral, um crescimento médio de 56,3\% em dez anos, bem acima da média nacional do período, estimada em cerca de 30\% (CPT, 2011).

Nesse sentido, comprova-se que a violência no campo amapaense é uma realidade posta, porém camuflada. É importante ratificar que os conflitos pela terra não se identificam somente por agressões físicas ou em casos extremos de assassinatos, como ficaram estereotipados, por exemplo, os conflitos no estado do Pará.

Isso apenas fortalece o "mito" de que a violência no campo amapaense não existe, que ela é um problema típico do quintal do vizinho Pará, e que, quando existe, trata-se de "briga de cerca". Isso pode ser ainda mais desmistificado se for analisada a distribuição desses conflitos, assim como os seus principais sujeitos sociais atingidos e os agentes da violência no campo amapaense.

Embora os conflitos pela terra envolvam diferentes grupos sociais, como os quilombolas, os indígenas e os assentados de projetos de reforma agrária do Incra, indiscutivelmente, se tem como principal atingido pela luta da terra no Amapá o posseiro que sofre tanto com o descaso do poder público, que não lhe oferece meios concretos de legalização jurídica de sua posse, quanto pela ação violenta de agentes particulares, como madeireiros, fazendeiros, grileiros, mineradoras etc.

Mesmo não existindo registros consistentes sobre o envolvimento desse grupo nos conflitos, percebeu-se que no decurso dos anos de 2002 a 2011, os posseiros foram os principais sujeitos afetados pela disputa da terra no Estado. Tal fato se dá porque o posseiro não valoriza a terra como uma forma de propriedade, mas como seu instrumento de trabalho, que precisa da terra para viver. Assim, a resistência dos posseiros é uma luta contra a utilização da terra para fins de produção capitalista ou de meio de acesso a outras formas de riquezas como minérios, madeira e até mesmo incentivos fiscais (MARTINS, 1981).

De outro lado, têm-se como principal agente da violência particular no campo amapaense as empresas de celulose que vêm desencadeando ações de grilagem de terras, despejos e expulsões de camponeses, sem mencionar a pressão que faz junto aos posseiros para que vendam suas terras e benfeitorias a preços irrisórios. Assim, as empresas são exemplos da violência causada pela lógica capitalista de produção e apropriação da terra, principalmente após a gestão da empresa, em 2008, mudar do capital americano para o japonês; foi revertida à política de boa vizinhança que a empresa vinha mantendo com os posseiros que supostamente vivem em suas terras. 
Os registros da CPT mostram que a empresa de celulose Amcel esteve envolvida em grande parte dos conflitos pela terra nos últimos dez anos no Amapá, conflitando com aproximadamente 1.024 famílias. Desta forma, fica mais do que patente que esses conflitos pela terra não se tratam de mera briga de cerca, mas resultam de interesses antagônicos, em que, de um lado, há atores hegemônicos exemplificados em empresas como a Amcel e, de outro, sujeitos sociais desassistidos pelo Estado, como os posseiros.

Tais fatos comprovam que no Amapá os conflitos pela terra representam a resistência do campesinato local frente à expansão territorializante do capital nacional e internacional, pois à medida que a marcha do capital se expande, amplia-se também a resistência camponesa, aumentando o número de casos de conflitos pela terra, embora esse campesinato ainda apresente organização e consciência política muito incipientes no cenário amapaense.

Outro argumento que colabora para a análise dos conflitos pela terra no Amapá é a distribuição territorial desses conflitos. Entre 2002 e 2011, dos 16 municípios do Estado, 15 apresentaram conflitos; o único município em que a CPT/Amapá não registrou conflitos pela terra nesse período foi Serra do Navio ${ }^{2}$. Na Tabela 1, a seguir, é elencada a distribuição desses conflitos.

\footnotetext{
2 A metodologia para a elaboração tanto da Tabela 1 quanto do mapa se baseou na fidedignidade dos registros da CPT. Os dados mostraram que não houve registro de conflitos pela terra em Serra do Navio nos últimos dez anos, o que não significa que eles não ocorreram no município em anos anteriores. No que se refere ao mapa abaixo, buscou-se ressaltar a participação de cada município na dinâmica dos conflitos. Contudo, os dados da CPT mostram, com exceção de Serra do Navio, que não se registraram conflitos e Itaubal que os apresentou em menor número, mas não é fronteiriço, que os conflitos genericamente se distribuíram em três zonas, onde se usaram variações de cores emblemáticas para representar o grau de conflitividade de cada zona dessas: verde (baixa conflitividade), amarelo (conflitividade relativa) e vermelho (conflitividade alta).
} 
Tabela 1 - Distribuição dos conflitos pela terra entre 2002 a 2011

\begin{tabular}{clcc}
\hline Colocação & \multicolumn{1}{c}{ Município } & $\begin{array}{c}\text { Total de } \\
\text { registros }\end{array}$ & $\%$ \\
\hline $1^{\circ}$ & Macapá (área rural) & 86 & 22,27 \\
$2^{\circ}$ & Ferreira Gomes & 62 & 16,06 \\
$3^{\circ}$ & Tartarugalzinho & 45 & 11,65 \\
$4^{\circ}$ & Porto Grande & 35 & 9,06 \\
$5^{\circ}$ & Calçoene & 26 & 6,73 \\
$6^{\circ}$ & Cutias & 25 & 6,47 \\
$7^{\circ}$ & Pracuúba & 23 & 5,95 \\
$8^{\circ}$ & Pedra Branca do Amapari & 21 & 5,44 \\
$9^{\circ}$ & Amapá & 17 & 4,40 \\
$10^{\circ}$ & Mazagão & 16 & 4,14 \\
$11^{\circ}$ & Santana & 11 & 2,87 \\
$12^{\circ}$ & Itaubal do Piririm & 09 & 2,33 \\
$13^{\circ}$ & Laranjal do Jari & 05 & 1,29 \\
$14^{\circ}$ & Vitória do Jari & 04 & 1,0 \\
$15^{\circ}$ & Oiapoque & 01 & 0,25 \\
$16^{\circ}$ & Serra do Navio & 0 & 0 \\
\hline & Total & $\mathbf{3 8 6}$ & $\mathbf{1 0 0}$ \\
\hline
\end{tabular}

Fonte: CPT (2012), organização: Júnior Silva (2013).

Na Tabela 1 é demonstrado que entre 2002 e 2011, a área rural do município de Macapá foi proeminente no número de registros de conflitos pela terra $(22,7 \%)$, seguida do município de Ferreira Gomes (16,06\%), de Tartarugalzinho (11, 65\%) em terceiro, e, Porto Grande (9,06\%), em quarto. Isso significa que os conflitos pela terra no Amapá, embora tenham ocorrido em praticamente todo o estado, concentram-se em uma área específica. Assim, o questionamento fica em torno do porquê alguns municípios apresentarem o maior número de conflitos pela terra no Amapá no período analisado. O mapa a seguir ajuda a responder a essa questão. 


\section{Mapa 1 - Distribuição espacial dos conflitos pela terra no Amapá}
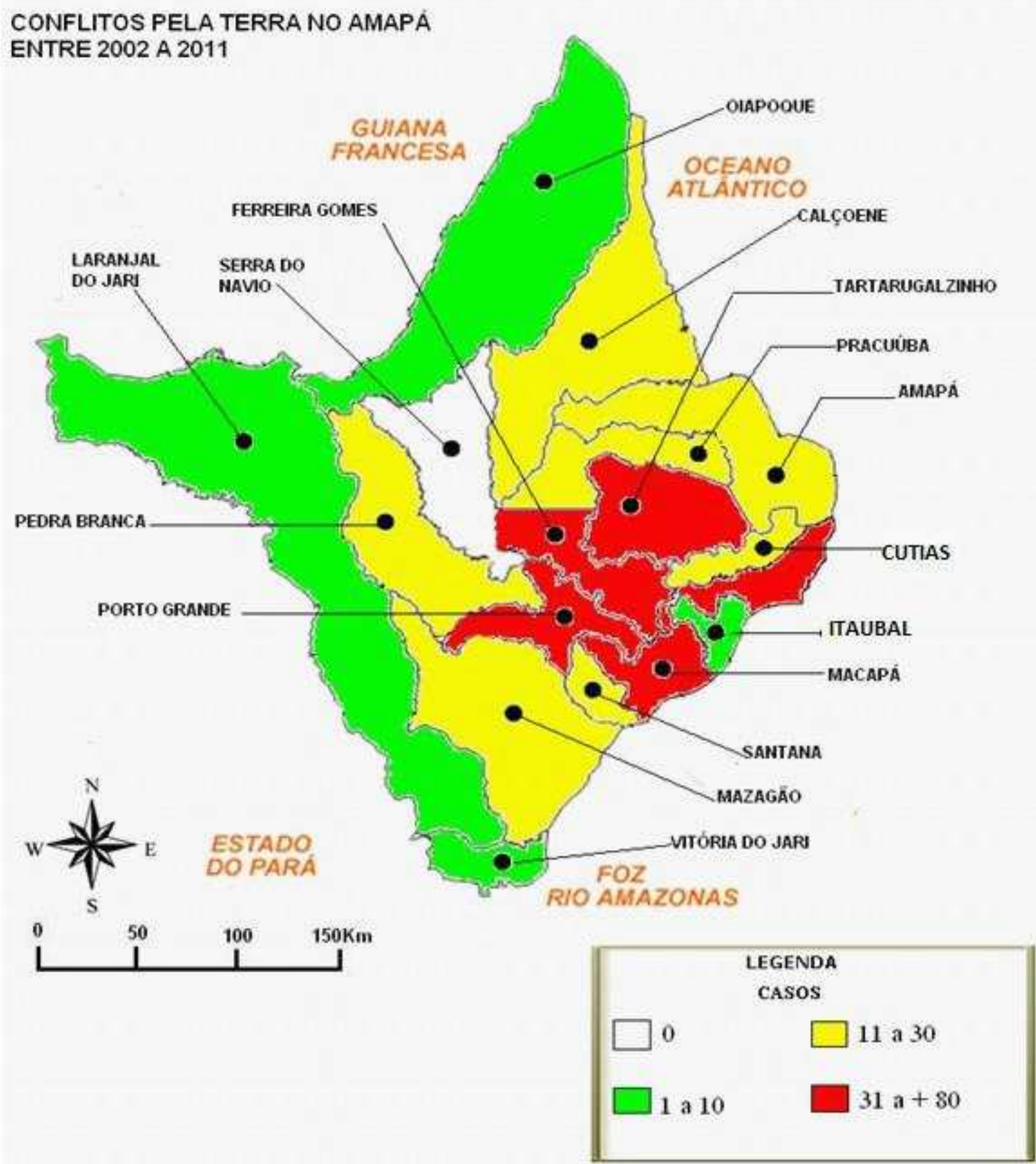

Fonte: CPT, organização: Junior Silva (2013).

Este mapa permite inferir que os municípios de Itaubal do Piririm, Laranjal do Jari, Oiapoque e Vitória do Jari apresentaram baixos registros de conflitividade. Os três últimos municípios formam a zona fronteiriça Oeste do Amapá, área onde parte de suas terras se destina a reservas indígenas e a unidades de conservação, muitas de proteção integral, o que provavelmente colabora para este quadro, embora a CPT/Amapá tenha registrado conflitos pela terra em unidades de 
conservação, como o que envolveu posseiros na Resex do Cajari em 2009 (CPT, 2011).

Nesses quatro municípios foram registrados pela CPT/Amapá, em dez anos, 19 conflitos, correspondendo a $4 \%$ do total registrado no estado. Juntos, esses municípios possuem, segundo o IBGE (2010), uma população rural de 13.075 habitantes, sendo que suas principais ações conflituosas se deram nas áreas de unidades de conservação e de reservas indígenas, ocasionadas principalmente pela prática de garimpagem em Laranjal do Jari e Oiapoque, além da atuação das empresas Jari Celulose em Vitória do Jari e das ações de grilagem de terras pela Amcel. Em Itaubal também houve registro de conflitos envolvendo fazendeiros contra posseiros e assentados.

Os municípios que apresentam conflitividade relativa estão na porção norte do estado, em Amapá e Calçoene; no Nordeste, Cutias e Pracuúba; no Sul, Mazagão; no Sudeste, Santana e, na porção central, Pedra Branca do Amapari. Segundo o IBGE (2010), esses sete municípios juntos possuem uma população rural de 22.946 habitantes, sendo que, neles, a CPT/Amapá registrou, entre 2002 e 2011, 139 conflitos pela terra, 36\% do total. Os conflitos nesses municípios apresentam uma gama de variedades que compreendem desde conflitos envolvendo assentados e posseiros contra criadores de búfalos em Amapá e Calçoene, passando por posseiros, grileiros e fazendeiros em Pracuúba, até embates da Amcel contra posseiros e assentados em Santana e Cutias.

Cabe ressaltar que esses municípios vêm apresentando conflitividade em ascensão, situação em que se tem o município de Pedra Branca como espelho. Até 2005, a CPT/Amapá não havia registrado conflitos no município, mas com o desenvolvimento de projetos de mineração em Pedra Branca, esses números dispararam, chamando a atenção para o fato que este foi o terceiro município do país que mais teve aumento populacional registrado no último censo nacional (IBGE, 2010).

Porém, a região-problema dos conflitos pela terra no Amapá é a porção sudeste do estado, que compreende a zona rural de Macapá, Porto Grande, Tartarugalzinho e Ferreira Gomes. Juntos, esses quatro municípios apresentam, segundo o IBGE (2010), uma população rural de 32.469 habitantes e respondem por $60 \%$ dos conflitos pela terra no estado. Nesses municípios, os conflitos envolvem diferentes sujeitos como posseiros, quilombolas e assentados do Incra contra grileiros, fazendeiros, madeireiros e, principalmente, contra a Amcel.

Esses municípios concentram os conflitos pela terra em grande parte por dois motivos: o primeiro é que por meio da zona rural de Macapá, passando por Porto Grande, Ferreira Gomes e Tartarugalzinho, ocorre a maior área natural transformada por atividades de exploração como as áreas de cerrado, território da silvicultura desenvolvida pela Amcel, bem como a exploração de madeireiras em Porto Grande, Ferreira Gomes e Tartarugalzinho. Segundo o IEPA (2006), 
Ferreira Gomes, com 42,4\%, e Porto Grande, com 20\%, são os municípios que apresentam a maior extensão de áreas naturais devastadas no Amapá, alteração essa que se deve principalmente à atividade de silvicultura e à exploração de madeira. O segundo motivo é que neles se concentram 19 dos 40 projetos de assentamentos existentes no estado, ou seja, 47,5\% dos projetos de assentamentos da reforma agrária criados pelo Governo do Amapá e, principalmente, pelo Incra (INCRA, 2012).

Isso influencia os conflitos porque, segundo Galazzi (2013), tais assentamentos foram estrategicamente criados pelo Incra para servirem no futuro como área de plantio da Amcel e exploração de madeireiras, pois os agricultores assentados servem como "antropizadores" da floresta, desbravando-a para que depois o capital monopolize esses territórios. Para o autor, isso ocorre porque a reforma agrária no Amapá veio de cima para baixo e visa atender interesses políticos, acarretando a criação de assentamentos sem a mínima infraestrutura, o que faz do assentado um refém de um sistema corrupto marcado pela evasão e pelo mau uso dos créditos de instalação, sem falar que muitos cedem seus lotes para a exploração de madeira e/ou plantio de eucaliptos.

Desta forma, criam-se relações de conflitos pela terra nesses assentamentos, uma vez que empresas como a Amcel e as madeireiras atuam no sentido de aliciar ou de expropriar o assentado do seu lote para que assim se consolide a exploração de recursos naturais presentes nos assentamentos como, por exemplo, a madeira, produto este que vem sendo explorado há tempos dentro dos projetos de assentamentos do Amapá. Vale ressaltar que esse sistema se alimenta da omissão de órgãos estatais que deveriam inibir tais conflitos, como o próprio Incra.

Desse modo, a CPT/Amapá evidencia que pelo menos 15\% dos registros de conflitos pela terra no estado do Amapá nos últimos dez anos se deram em projetos de assentamentos. Nesse âmbito, os projetos de assentamentos, principalmente os geridos pelo Incra, em vez de servirem como um instrumento de resolução da concentração da terra e dos conflitos por ela, na verdade, representam o contrário, pois passaram a ser parte do problema dos conflitos, exemplificando que a violência no campo amapaense é, além de tudo, institucionalizada.

\section{Considerações finais}

O presente trabalho demonstra que o "mito da paz no campo amapaense" é uma utopia. A realidade mostra que, definitivamente, há um processo de luta pela terra no estado do Amapá e que ela é marcada pela violência e por estratégias tanto do grande capital quanto do próprio Estado. Este último foi, e ainda o é, o intermediador institucional da implantação de grandes propriedades e projetos 
econômicos no Amapá, pois utiliza a terra como meio para reprodução do capital, subjugando os camponeses a viverem como sujeitos sociais execrados do direito de possuir os meios de trabalho.

Portanto, no Amapá, os conflitos pela terra não podem ser pensados sem se levar em conta a aliança entre Estado e empresas capitalistas como a Amcel. Nesse sentido, a discussão dos conflitos pela terra no estado necessita sair da obscuridade que ainda representa para os meios acadêmicos e para a sociedade como um todo, pois só assim se saberá que no Amapá a terra também é marcada pelo suor, pelas lágrimas e pelo sangue daqueles que por ela decidiram lutar - aos que continuam na luta fica a esperança de que um dia a terra pertencerá àqueles que dela necessitam para viver.

\section{Referências}

CANUTO, Antonio; LUZ, Cássia Regina Silva; AFONSO, José Batista Gonçalves (Orgs.). Conflitos no Campo Brasil 2007. Goiânia: CPT Nacional, Brasil, 2007.

CANUTO, Antonio; LUZ, Cássia Regina Silva; WICHINIESKI, Isolete (Orgs.). Conflitos no Campo Brasil 2011. Goiânia: CPT Nacional Brasil, 2011.

2012.

(Orgs.). Conflitos no Campo Brasil 2011. Goiânia: CPT Nacional Brasil,

GALAZZI, Alessandro. Depoimento sobre "A Reforma Agrária de faz de conta do INCRA no Amapá” ocorrida na sede da Comissão Pastoral da Terra em 22 de maio de 2013.

GONÇALVES, Carlos Walter Porto. Índices de Violência no Campo. Brasil 2005. In: CANUTO, Antonio; LUZ, Cássia Regina Silva; AFONSO, José Batista Gonçalves (Orgs.). Conflitos no Campo Brasil 2005. Goiânia: CPT Nacional Brasil, 2004.

IBGE. Instituto Brasileiro de Geografia e Estatística. Censo demográfico 2010. Disponível em: <www.ibge.gov.br>. Acesso em: 21 nov. 2012.

IEPA. Instituto de Estudos e Pesquisa Científicos do Amapá. Macrodiagnóstico do Estado do Amapá: primeira aproximação do ZEE/AP - Macapá: IEPA ZEE, $2^{a}$ edição, 2006. 
INCRA. Instituto Nacional de Colonização e Reforma Agrária. Tipos de projetos criados e o número de famílias assentadas nos projetos de reforma agrária no Amapá. Disponível em: <http://www.incra.gov.br>. Acesso em: 16 jul. 2012.

JORGE, Sérgio Paulo de Souza. Política fundiária como instrumento de ordenamento territorial. Brasília: UNB (Dissertação de Mestrado). Universidade de Brasília. Centro de Desenvolvimento Sustentável), 2003.

LIMA, Ricardo Ângelo Pereira de. Ordenamento territorial amapaense: dinâmicas de um estado brasileiro na fronteira amazônica. Barcelona: Universidade de Barcelona. 2008. Disponível em: <http://www.ub.edu/ geocrit/xcol/100.htm>. Acesso em: 14 dez. 2012.

MARTINS, José de Souza. Os camponeses e a política no Brasil: as lutas sociais no campo e seu lugar no processo político. Petrópolis/RJ: Editora Vozes, 1981.

MANIGLIA, Elisabete. As interfaces do direito agrário e dos direitos humanos e a segurança alimentar. São Paulo: Cultura Acadêmica, 2009.

RAIOL, Osvaldino da Silva. A utopia da terra na fronteira da Amazônia: a geopolítica e o conflito pela posse da terra no Amapá. Macapá: Editora Gráfica O Dia Ltda, 1992.

TORRINHA, Mário Nunes. Desordenamento territorial e conflitos rurais no estado do Amapá nas décadas de 1980 e 1990. Amazônia Ci \& Desenv., Belém, v. 2, n. 3, jul./dez., 2006.

Endereço para correspondência:

Roni MayerLomba - ronimayer@hotmail.com

Rodovia Juscelino Kubitscheck, Km 2, Jardim Marco Zero

68930-419 Macapá/AP, Brasil

Junior Gomes da Silva - juniornobregeografia@hotmail.com

Rodovia Juscelino Kubitscheck, Km 2, Jardim Marco Zero

68930-419 Macapá/AP, Brasil 